\title{
Accessibility and Connectivity as the Key Factors of the Macro-space in Built Environment
}

\author{
Krasheninnikov A. V. \\ Moscow Architectural Institute (State Academy), Moscow, Russia
}

Copyright $\odot 2019$ by authors, all rights reserved. Authors agree that this article remains permanently open access under the terms of the Creative Commons Attribution License 4.0 International License

\begin{abstract}
This article continues a series of publications on Cognitive Urbanism. The research aimed at studying and classification of the built environment as an object of design. We must go beyond space-making to the making of places. The cognitive approach naturally leads us to the idea of the cultural landscape and the study of the traditions and rituals of everyday life. The essence of the study relates to the so-called "environmental behavior" that is all types of social activity and interactions with the built environment. We suggest that the spatial structure of Macro-space can be analyzed through the two key factors: the accessibility and connectivity of place. Accessibility can be measured by the time one needs to reach the center of Macro-space and the Connectivity - by the number of people that could be part of social life in the core area. Thus, Accessibility is an indicator of linear dimensions, physical boundaries and direction of links, and Connectivity is a derivative of the number of people, the density and the layout of settlement. Three Types of macro-spaces that are compared: The Enclave, The Region, and the District. The article provides a conceptual framework for the recommendations on urban planning and design based on Accessibility and Connectivity.
\end{abstract}

Keywords Cognitive Urbanism, Built Environment, Morphogenesis, Macro-space, Pedestrian Accessibility and Social Connectivity

\section{Introduction}

The quest for the comfortable public space in Russian cities awaked the theories of mental maps and environmental behavior. People recognize the city according to their "mental map" (Robert B. Bechtel 2003). The mental maps are individual, but spatial ideas about the urban environment are universal and depend mostly on education and experience of people. Like in the modern geographic information systems (GIS), mental map are "linking" the meaning and value of the site to a point on the map. However, unlike in GIS, the senses and content of places vary according to the physical conditions, social context, and inclusion in a particular culture. The environmental behavior in big cities modified very much according to the international cultural patterns and norms. Kevin Lynch had shown the fabric of the pedestrian city based on mental mapping techniques. (Lynch 1960). That was an essential input into the Topology of the Built Environment. Russian architect Vyacheslav Glazichev has translated the books of $\mathrm{K}$ Linch and wrote together with $\mathrm{A}$. Gutnov two books about the language of architecture and the world of architecture. This article explores those ideas formulating topology of urban macro-space with concern for the accessibility and connectivity of places in the city.

Let us define the Environmental Behavior as a socio-spatial activity of a person or a group of people (Altman I. 1980). This complex of actions includes a choice of motion and location, a selection of private screening and observation, the mode of social communication, and the use of the possibilities of the urban landscape. The models of environmental behavior could help the urban design professionals and landscape architects to enhance the spatial structure of cities. (Krasheninnikov 2016). The generalized "metal map" could explain much to the town planners, but the reliability of such a theoretical model is always questioned. (Tolley 2015) We must admit that in every model, some simplifications are inevitable. We had to identify the main features and temporarily disregard the second-rate factors such as local habits and the way of life, different interests of persons and group, difference in attitude depending on age, education, and background. Those factors would be considered later on and can be added to the basic models. More important for an urban planner is the basic topology of settlements, the patterns that survive the test of time and cultural change.

The patterns of a sustainable urban structure are often found in areas with a traditional population, where several generations lived in the same place. Today, such settlements have become rare, but they are valued more and more as a place of resort and escape from globalization. 
The small towns that had survived the industrial boom and then the postindustrial drainage nowadays possess a resource of living space of tremendous environmental potential. Unfortunately, the heritage quality of the small town is fragile and easy to lose with bad governance and empowered population. Formal renovation of the public space through pavements and greenery do not bring the wanted livability for Streets and Squares.

\section{A Methodology of Cognitive Urbanism}

We can note the opposition the two different approaches in studies of the built environment. The city as 'a cognitive phenomena', and the city as 'a set of patterns that architects use' to understand, diagnose and provide therapy for the built environment (Alexander and Center for Environmental Structure. 2002). The understanding of urban space cannot ignore Foucault's pioneering but confusing article 'Of other space' (Foucault, 1964). The article describes three spatial systems: -one with a single center - a system he calls 'emplacement'; - a second is a binary system of flows and dialectics; - the third is a network system of shifting relationships often between mobile actors and residents. The notion of three types of macro-space is essential for building a generalized model of urban space.

David Shane elaborated this theory giving the names of "enclaves" and "armature" for emplacements and flows. "Space Syntax" has also produced several important contributions to urban morphology, and is best represented by the work of Bill Hillier and Julienne Hanson from the Bartlett School of Planning at University College London (e.g. Hillier and Hanson, 1984; Hillier, 1996).

The Moscow architect M. Savchenco wrote a book "Architecture as a Science" where he explained the co-relation between such elements of architectural space as tópos and locus. The 'topos ${ }^{1 \text { ' }}$ combine the system of loci bringing the sense of place. Macro-space as a topos of urban life - is a recognized territory with locus and flows. The 'archetype' of a place includes the expected social activities of a person or a social group. [3] The mental map of a city is built of archetypes in a context of relationships, functions, symbolic meaning, time, experience, and other parameters of a particular place. In referring to "locus" we would allude to any space having center and boundaries, while by referring to "flows" we allude to a place of transit with anchor points ant nodes.

The concept of macro-space combines elements of locus (enclave), flow (transit) and topos (areal) that form the spacious structure of built environment.

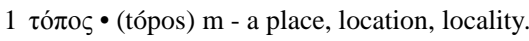

\section{The Two Variables of Environmental Behavior at the Macro-level of Built Environment}

«The site is defined by relations of proximity between points or elements» said Foucou (Foucault) and we should add that the site is also characterized by the cohesion of people. An anthropological approach to the urban planning leads us to the idea of cognitive codes by which the brain "talks" with us about space. (Cave 1998). The British scientist B. Hillier had found that - "spatial layout in itself generates a field of a probabilistic encounter, with structural properties that vary with the syntax of the layout" (Hillier 2007). The further study of this phenomenon, made in MARHI (Russia) suggests the classification of places by the two key factors: "ACCESSIBILITY" as a generalized characteristic of the spatial structure; and "CONNECTIVITY" as a generalized characteristic of social cohesion.

ACCESSIBILITY means the ability to reach the point. Accessibility can be measured in total time of moving "from door to door." The accessibility of the place is limited by the physical obstacles of space structure and personal perception of time. Some authors indicate that the time of walking affects cognitive skills and such aspects of environmental behavior as, selectivity, meaningfulness, purposefulness, categorization, reflexivity, etc. (Golovin 1998). The time spent on the path depends not only on the length and speed but also on the inter-location of places, walls, and fences, on the configuration of the route and a right of way. That is why the access time indirectly characterizes the structure of architectural space.

CONNECTIVITY means the cohesion of the possible participants in the local events. The concept of connectivity is widely used in economic geography to study and explain the phenomena of agglomerations. The intensity of pendulum migration and connectivity reveal the location of the central core, the first and secondary belts of the interconnected area. Similarly, you can observe the presence of the core and periphery in the small towns, separated neighborhoods or historical settlements. In bigger cities the structure is more complex and not so evident: we should account not only residents but also all the day population, as well as transit passengers and the size of the city. As a result, an urban structure of a big city has several types of macro-spaces:

- The recognized districts, the closed and fenced enclaves;

- The interconnected and transit regions.

The Acxiom of cognitive urbanism is that site accepts the sense of place and gains contextual properties through involvement is social practice. Foucault wrote that "We live inside a set of relations that delineates sites» (Foucault) and the social relations are the first to be mentioned when we talk about the public space of a city. 
The connectivity and accessibility of the place are the key spatial factors that provide the involvement in local social practice. The interaction of these two variables set a field of possible types of «macro-spaces» of the in settlement.

\section{The Grounds for the Three Basic Models of Macro-space}

Macro-space is a cognitive model of built environment, identified in mental map as an area of pedestrian proximity, circulation, and identification.

The Enclave - is a location with rigid borders (walls, fences) and one-step access to any point inside the boundaries. An examples of the Enclave are the common yard in the compound, or an enclosed plane in a small park.

The Region - is a public space with a defined center and conditional boundaries associated with the limits of easy pedestrian accessibility. Examples of the Region are the areas around transport/transfer nodes, metro stations, university hubs and bus stations. The pedestrian nodes form the stars-shape and the roots the linear strip structures of public space.

The District -is a recognized part of the city, limited by affordable pedestrian proximity. The District is usually named according to the heritage objects or events. External borders form a fringe belt of used and unused sites, and instead of core we find a framework of public spaces bounding the iconic objects, such as temples, markets, grows, riverbanks etc.

The combination of the three mentioned macro-spaces (enclaves, regions, and districts) - gives us derivative models that explain the Morphogenesis of elementary planning units (Kukina Irina V. 2018)

They are associated with the well-recognized morphotypes: the islands of city blocks around the school called micro-district", the transit-oriented development model (TOD), downtown center or a walkable mall-size town are the combination of enclaves, linear pedestrian strips along the avenue, the medium-sized city as combination of regions, the big city as a combination of districts (okruga). Basic patterns of macro-spaces can be elaborated in terms of zoning, dimensions, borders, and structure. The task for urban planners is to identify the type of macro-spaces: - to enforce a "frame" and to program the "tissue" of urban fabric (Gutnov 1992)

A separate topic of study may be the historical anthroposophy of the city, examining the benchmarks on the scales of time/distance and connectivity/livability. In this regard, it would be relevant and interesting to compare the limits of the population for the various urban forms, public spaces, and settlements. For example, the natural size of the clan and the areal of tribe, the number of citizens in the resilient town. That studies can explain the hidden strive and limits of cohesion in man-made environment. The connectivity determines our attitude to the events, and, naturally, largely determines the possibility of personal involvement in social practice. The social practice brings the sense to the place and the structure of a place regulate social practice that provide the sence of identification for the site of urban landscape (Solso 2001). With the help of macro-space models, one can identify and study the present and the future patterns for the built environment.

\section{The Method of Accessibility Assessment}

Based on the statistics of movement and displacements in the city, starting from M. Davidovich, A. Yakshin, T. Govorenkova (Jakshin A. 1979), and taking into account observations, that were made in different places around the world, we could assume the following rule of thumb about the role of distance and time in people's personal perception and use of urban landscape-

- $\quad$ One step distance means short walking routes lasting 2-3 minutes, during which one can walk 150-200 m;

- Comfortable walking distance means a distance of about 500-600 meters, which can be reached in 8-10 minutes);

- Affordable walking distance for a city dweller is determined at 20-30 minutes, which is, a path length of 1-2 km (from 1300 to $1800 \mathrm{~m}$ long distance depending on physical abilities).

According to a study by A. Potapenko, the maximum distance of $50 \mathrm{~m}$ between the anchor points of pedestrian roots indicates the real public areas of the city (for the city of Vladivostok). Such public areas occupy only $20 \%$ of the entire city (Vladivostok is 6,808 hectares) but include 74.5\% of all city facilities.” (Потапенко, 2018) р. 408. 


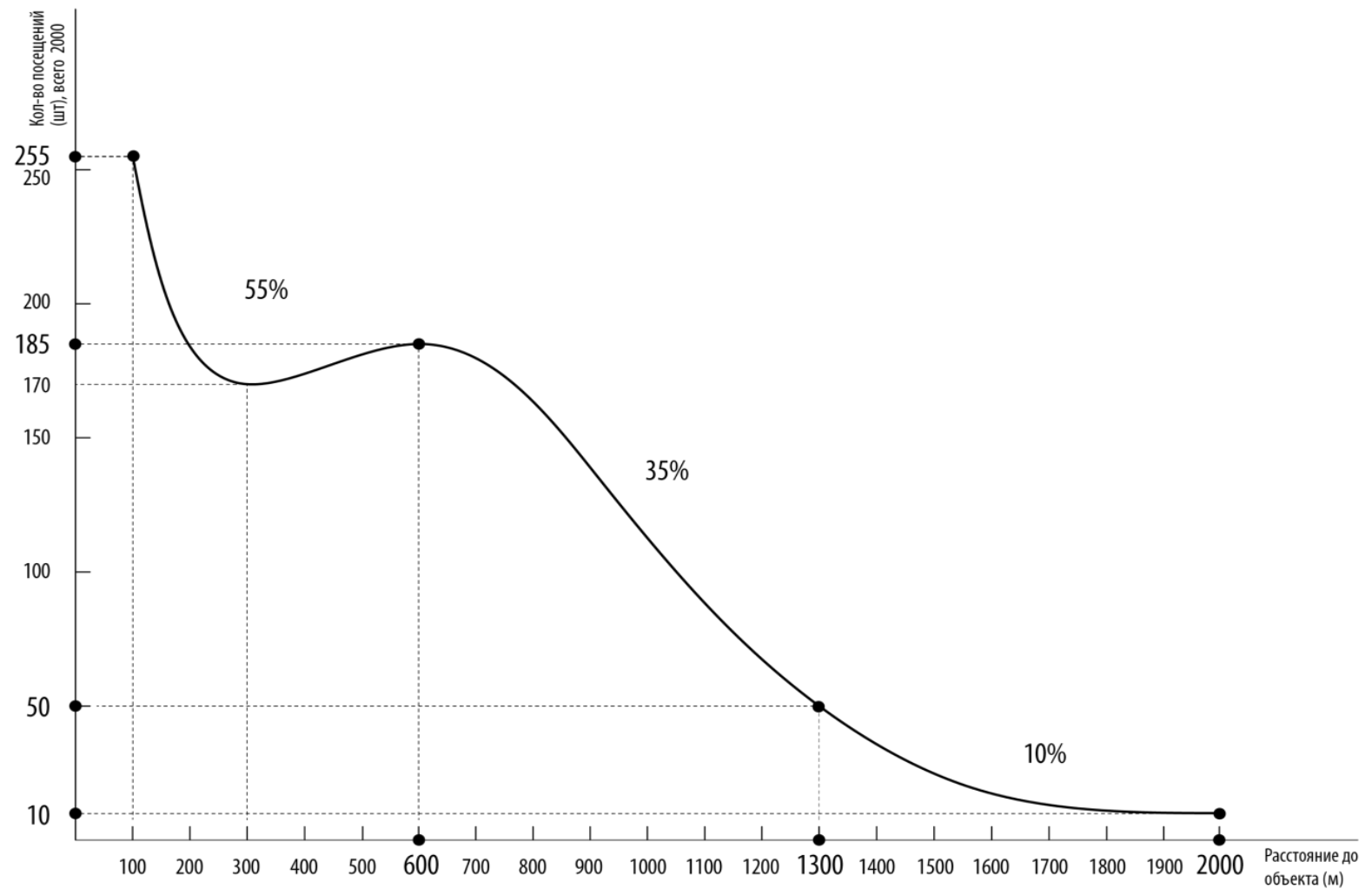

Figure 1. The expected quantity of participants in local social practice. R Kavenski's the drawin based on the publication «Frequency of walk distance from home to public transport for walk trips less than $2 \mathrm{~km}$. Legend: Vertical axis- Number of walk trips, Horisontal axis Walk distance, metres. (Daniels R. and Sydney 2011)

\section{The Method of Connectivity Assessment}

Connectivity is a combination of daytime, night and transit population. Connectivity identifies places with the greatest urban potential for the development of public spaces: local centers for nighttime population (local residents); - anchor points and attractors of the daytime population; public transport stops and nodes of pedestrian routes.

As a result of the imposition of these zones, we get parts of the urban area with the best social cohesion and potential for urban development. The area around these places acquires the status of public space. \{Krasheninnikov, 2015\}

The number of people at a distance of affordable access sets the conditions for social interactions, which "warms up" the social rector of public space. In his book CONNECTOGRAPHY, Parag Khanna argues that connectivity and the cohesion is the key indicator of social success (Khanna 2017). We can also make a preliminary assumption of social cohesion by dividing the urban area into macro-spaces and marginal urban fabric.

If we estimate the local connectivity as a quantity of people simultaneously participating in social practice we would assume that the number people in the core area of macro-space would be \%
- $\quad 50-60 \%$ from the same macro-space,

- $\quad 30-40 \%$ from the neighboring macro-spaces (30-50 minutes walk)

- $\quad 10-20 \%$ from the other places at a distance of 1-1.5 hours.

The proposed method of macro-space connectivity assessment is especially beneficial at the first steps of spatial planning and Muster plan design. We should be aware of the limitations of such prognoses. The landscape and geography of the territory, the density of housing and the road network, the effectiveness of bicycle traffic and public transport are all the altering factors for the accurate assumption.

The urban environment can be imagined as a canvas with colored spots overlapping each other, spots of different sizes, shapes, and saturation. This spots correspond to the location of people and symbolizes places. The places of different shapes and sizes correspond with informal (spontaneous) social groups. In the process of programming and modeling of the built environment, places can be represented by the collared pieces of different sizes and shapes, in a form of collage.

This collage of places helps to study and evaluate the structure of comfortable public space. The implementation of such a model requires further development in architectural design and require professional skills. Otherwise, the design of well-programmed urban 
environment will reproduce simplified functional templates.

\section{Conclusions}

Cognitive Urbanism as a branch of Urban morphology seeks to understand the spatial structure of a built environment by examining its patterns and the process of its development. The subject of this article was a systematization of macro-space of the urban area by the two key factors: accessibility and connectivity of places. The proposed models underlie the possible planning units of the city fabric. With the accumulation of empirical data, urban design increasingly goes to the structural and functional analysis of cities and begins to focus on the problems of the public space as an organization of urban life and environmental behavior concerning the local character of the place.

The experimental design showed that the use of macro-space patterns is useful both for structural analysis and for making project of urban plans.

Cognitive interpretation of socio-cultural and the spatial context of human settlements aimed at the correction of urban design solutions, land-use planning, and the planning structure of settlements according to customs, traditions, and norms of environmental behavior.

\section{Acknowledgements}

The reported study was partially supported by the "Central Research and Design Institute of the Ministry of Construction and Housing and Communal Services of the Russian Federation." Research: Basic strategies for the development of the transport infrastructure of Russian cities. 2018

\section{REFERENCES}

[1] Alexander, Christopher, and Center for Environmental Structure. 2002. The phenomenon of life : an essay on the art of building and the nature of the universe. Berkeley, Calif.: Center for Environmental Structure.

[2] Altman I., Chemers M. M. - Monterey, Calif.: Brooks/Cole Pub. Co., The Brooks/Cole basic concepts in environment and behavior series. -- 1980. Culture and environment. The Brooks/Cole basic concepts in environment and behavior series. /. Monterey, Calif.: Brooks/Cole Pub. Co..

[3] Cave, S. 1998. Applying Psychology to the Environment.: London: Hodder \& Stoughton.

[4] Daniels R., Mulley C., and Institute of Transport and Logistics Studies The University of Sydney. 2011. "Explaining walking distance to public transport: the dominance of public transport supply."
[5] Foucault, Mi. "Of Other Spaces, " Diacritics 16 (Spring 1986), 22-27. 1986. "Of Other Spaces,." Diacritics 16 (Spring 1986):22-27.

[6] Gutnov, Alexey. 1992. Gorod v teorii system [Town in a system theory]. Moscow: МП «Ладья», 1993.-320-c.

[7] Hillier, Bill. 2007. Space is the machine. A confgurational theory of architecture.

[8] Jakshin A., Govorenkova Т. (Якшин А.М., Говоренкова Т.М. [и др.] ). 1979. Graphic-analytical method for urban studies and planning (Rus): - М.: Стройиздат.

[9] Khanna, Pagag. 2017. "Connectography. Mapping the future of global civilization."

[10] Krasheninnikov, A. V.; Saprykina, N. A. 2016. "Topology and Space-Time Structure of the Built Environment." Sgem 2016, Bk 4: Arts, Performing Arts, Architecture and Design Conference Proceedings, Vol Iii:593-99.

[11] Kukina Irina V., Fedchenko Irina G. 2018. "Morphogenesis of elementary residential planning units." in ISUF 2018 XXV International conference: Urban Form and Social Context: from traditions to newest demands.

[12] Lynch, Kevin. 1960. The image of the city. Cambridge Mass.: Technology Press.

[13] Robert B. Bechtel, Arza Churchman 2003. Handbook of Environmental Psychology: Jphn Wiley \& Sons, Inc.

[14] Shane, D G. 2005. Recombinant Urbanism: Conceptual Modeling in Architecture, Urban Design and City Theory.

[15] Solso, Robert L. 2001. Cognitive psychology. Boston: Allyn and Bacon.

[16] Tolley, Martin. 2015. "Environmental Psychology." http://martintolley.com/environment/Index.html: The University of Northampton.

[17] Potapenko A/ Потапенко A. А. Построение неравномерно-районированной модели (на примере г. Владивостока) // Architecture and Modern Information Technologies. 2018. №4(45). С. 402-415 [Электронный pecypc]. - URL:http://marhi.ru/AMIT/2018/4kvart18/28_p otapenko/index.php 